\title{
Discriminant Methods and Error Analysis of Interaction between Two Wings of Diagonal Ventilation System in Coal Mine
}

\author{
Yongbo CAl ${ }^{*}$, Kai WANG*
}

\begin{abstract}
Ventilation systems play an essential role in underground works. To explore the interaction laws of two wings in a dual-wing diagonal ventilation system, methods of theoretical and case analyses were combined to propose a theoretical interaction equation (nonlinear) and approximate interaction equation (linear). The error between these equations was explored through a case study on Qianjiaying coal mine. The application conditions of the models were summarized and their errors were analysed. Results show that increase of air quantity at one wing causes the air quantity to decrease at the other wing in a diagonal ventilation system, and also leads to an increase of the total air quantity of the mine. The greater the resistance of the common airway, the greater is its influence. The absolute and relative errors of the west-wing air quantity change increase with the increase of east-wing air quantity change and increase of the common airway resistance. The absolute error does not reach $2.5 \mathrm{~m} / \mathrm{s}$ at most, but the increases in the magnitude of relative error are large. The absolute error of the total air quantity change increases with the increase of east-wing air quantity change; the relative error increases with the increase of the resistance of common airway when east-wing air quantity change is larger than $15 \mathrm{~m} 3 / \mathrm{s}$, and the relative error is less than $5 \%$. The conclusions provide guidance for ventilation calculation.
\end{abstract}

Keywords: Air quantity; Diagonal ventilation; Error analysis; Interaction

\section{INTRODUCTION}

Ventilation systems play an essential role in underground works [1-3]. A ventilation system can provide fresh air and a comfortable working environment while preventing workplace disasters in underground mining [47]. With the increase of mining depth and scope, the mine ventilation system has become highly complex, and underground safety problems, such as gas, dust, and thermal damage, are becoming increasingly prominent [810]. Accordingly, the mine ventilation system has strict requirements. A greater number of coal mines have multiair intake and multi-blower exhaust air. The typical application of multi-fan joint operation is the dual-wing diagonal ventilation system.

This system is mainly used to meet the present requirements of production and ventilation in a number of large underground mines. The interaction of fans' joint operation exists in dual-wing diagonal ventilation systems. Under normal circumstances, the working status and performance of the two fans are the same, thereby ensuring that the air quantity and air pressure are in a balanced and stable state on both wings. However, if these conditions are influenced by unexpected factors, then mutation would occur in the working conditions of a fan on a wing. The influence on the ventilation condition of the other wing fan and the entire mine and its consequences need to be studied.

\section{STATE OF THE ART}

Scholars around the world have studied issues related to fan joint operation. For instance, Jia and Liu [11] applied multiple regression analysis to analyze the stability of a diagonal connection structure in a ventilation system. Hurtado and Acuna [12] adopted CFD (Computational Fluid Dynamic) simulation to estimate the operation point of main fans in parallel to optimize the current ventilation system in El Teniente mine in Rancagua, Chile. The major ventilator interference discriminant methods in the dualwing diagonal ventilation system and the H-type ventilation system were analyzed by Zhang [13]. The characteristics of the multi-fan mine ventilation system were studied by Wang [14] to analyze the relationships among main parameters, such as air power, pressure loss, air quantity and resistance, and propose the concept of a subsystem. Gushchin [15] used methods of differential calculus to estimate the influence of fans in parallel operation. Imaging and mathematical model methods were applied to analyze the working sites of parallel and series fans in the multi-fan ventilation system. Sarac and Sensogut [16] proposed n-dimensional nonlinear equations of each fan air quantity in the n-fan parallel operation ventilation system, and provided computer program algorithms of those equations, based on Newton-Raphson method. Si et al. [17] adopted the limit analysis method to study the interaction of multi-fan joint operation in the complex ventilation system. Hardy Cross algorithm was used in combination with switching parameter algorithm to study the mutual influences among fans in the multi-fan ventilation system, as well as the stability of the ventilation network by El-Nagdy [18]; the validity and reliability of this algorithm was proved by citing the Abu-Tartur coal mine in Egypt as an example. Xu et al. [19] used the method of nonlinear optimization algorithm for calibrating mine ventilation network models, and compared and analyzed the results of data before and after calibration. The results showed that the simulated airflows in the calibrated model were in agreement with the ventilation survey data, thereby verifying the effectiveness of the calibration method. Zhang [13], Li [20] and Luan [21] applied quadratic term to simplify the deduction process of interaction relations of two wings in a dual-wing diagonal ventilation system, and obtained an approximate formula that ignores the quadratic term.

This study aims to measure the error caused by approximate equation analysis and determine whether it can meet precision requirements. The theoretical interaction equation of two wings in the dual-wing diagonal ventilation system is first deduced by considering the influence of the second-order term. Then, combined with the actual case of the Qianjiaying mine, the mine 
ventilation network is simplified to build a simplified model of a dual-wing diagonal ventilation system. Finally, the error of the approximate interaction equation against the theoretical interaction equation is analyzed. These research contents aim to provide guidance for ventilation management in coal mines.

The rest of this paper is organized as follows. Section 3 establishes the theoretical interaction equation and approximate interaction equation of the two wings in the dual-wing diagonal ventilation system. Section 4 combines with the actual case; the mine ventilation network is simplified to build a simplification model of a dual-wing diagonal ventilation system. Section 5 summarizes the conclusions.

\section{METHODOLOGY \\ 3.1 Simplified Model of Dual-Wing Diagonal Ventilation System}

Fresh air flows to the shaft bottom through the main and auxiliary shafts, and shunts at the shaft station in a dual-wing diagonal ventilation system. A portion of the air flows through the right horizontal transport alley and places requiring air flow, and eventually is released by the right exhausting shaft; then, another portion of the air flows through the left horizontal transport alley and places requiring air flow, and eventually is released by the left exhausting shaft. In the complex dual-wing diagonal ventilation system, according to the characteristics of ventilation networks and concepts of isobar lines and points [22-23], the main and auxiliary shafts are equivalently combined into a common airway in the coal mine. After air diversion, parallel branches in the right wing are equivalently combined into an airway, and parallel branches in the left wing are equivalently combined into another airway, thereby achieving a simplified model of dual-wing diagonal ventilation system, as shown in Fig. 1. The resistance of the left-wing airway (B-C) is $R_{1}$, and air quantity is $Q_{1}$. The resistance of the right-wing airway (B-D) is $R_{2}$, and air quantity is $Q_{2}$. The resistance of the common airway (A-B) in the mine is $R_{0}$, and the total air quantity is $Q_{0}$. The current assumption is that according to the actual needs, the air quantity of the mine should be increased in the right wing at increments of $\Delta Q_{2}$, then the blade installation angle of the right-wing fan is to be increased for adjustment. The influences of the right-wing air quantity adjustment on the air quantity of the left-wing major fan and total air quantity of the mine can be studied through the following analytical method.

The adjustment of the right-wing airway can cause a change (increase or decrease) in the air quantity of rightwing major fan $\left(\Delta Q_{2}\right)$ under the condition of no account of air leakage. To study the air quantity changes in other airways, we first need to solve the change of the left-wing air quantity $\left(\Delta Q_{1}\right)$ and change of the air quantity in the common airway $\left(\Delta Q_{0}\right)$.

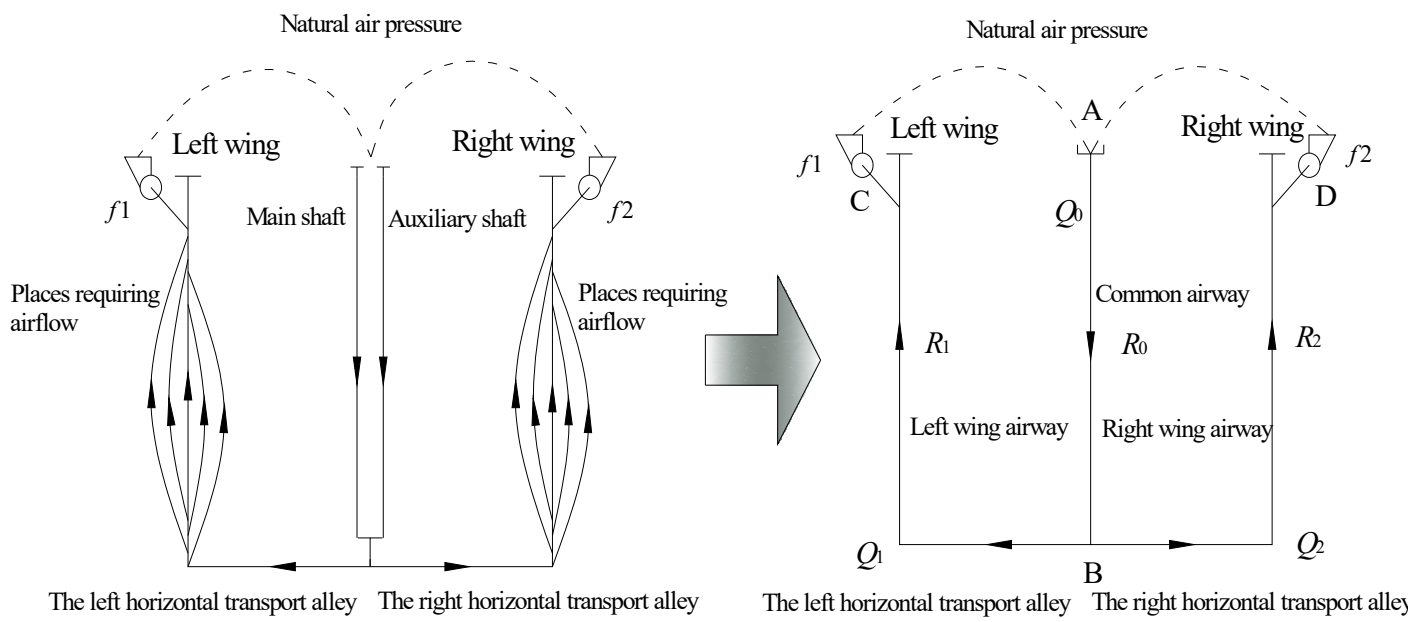

Figure 1 Simplified model of dual-wing diagonal ventilation system

\subsection{Theoretical Interaction Equation}

Combined with the research results of other scholars, the theoretical equation is further derived [13], [20-21].

According to the air quantity balancing law, the air quantity balancing equation at node $\mathrm{B}$ before adjustment of the right wing can be obtained as follows:

$$
Q_{0}=Q_{1}+Q_{2}
$$

When the right-wing fan has been adjusted, the rightwing air quantity changes into $Q_{2}+\Delta Q_{2}$. If the left-wing fan is not adjusted accordingly, then the left-wing air quantity changes from $Q_{1}$ to $Q_{1}+\Delta Q_{1}$. The reason is that the resistance of common airway (A-B) changes accordingly after the right-wing air quantity is adjusted, thereby causing a change in the left-wing resistance. If the left-wing major fan $\left(f_{1}\right)$ and resistance of left-wing airway $\left(R_{1}\right)$ are not changed, then the working resistance of the left-wing major fan $\left(f_{1}\right)$ would change, thereby also causing air quantity changes (under the condition of no account of air leakage, $Q_{f 1}=Q_{1}$ ). Therefore, the air quantity balancing equation at node $\mathrm{B}$ after adjustment of the right wing is adjusted as follows:

$$
Q_{0}+\Delta Q_{0}=Q_{1}+\Delta Q_{1}+Q_{2}+\Delta Q_{2}
$$

When Eq. (1) is subtracted from Eq. (2), the following can be obtained:

$$
\Delta Q_{0}=\Delta Q_{1}+\Delta Q_{2}
$$


The fitting equation of the air pressure curve of leftwing major fan is $h_{f 1}=a_{0}+a_{1} Q_{1}+a_{2} Q_{1}^{2}$, and the natural air pressure of the left wing of the mine is $h_{n 1}$. Thus, the air pressure balancing equation of the circuit of A-B-C-A before the adjustment of right-wing air quantity can be obtained as follows:

$$
R_{0} Q_{0}^{2}+R_{1} Q_{1}^{2}=\mathrm{a}_{0}+\mathrm{a}_{1} \mathrm{Q}_{1}+\mathrm{a}_{2} \mathrm{Q}_{1}^{2} \pm \mathrm{h}_{\mathrm{n} 1}
$$

where $a_{0}, a_{1}$, and $a_{2}$ are the fitting equation parameters of the characteristic curve for the left-wing major fan $\left(f_{1}\right)$.

Similarly, the air pressure balancing equation of the circuit of A-B-C-A after adjustment of the right-wing air quantity is obtained as follows:

$$
\begin{aligned}
& R_{0}\left(Q_{0}+\Delta Q_{0}\right)^{2}+R_{1}\left(Q_{1}+\Delta Q_{1}\right)^{2}= \\
& =a_{0}+a_{1}\left(Q_{1}+\Delta Q_{1}\right)+a_{2}\left(Q_{1}+\Delta Q_{1}\right)^{2} \pm h_{n 1}
\end{aligned}
$$

Eq. (5) is expanded to obtain the following:

$$
\begin{aligned}
& R_{0} Q_{0}^{2}+2 R_{0} Q_{0} \Delta Q_{0}+R_{0} \Delta Q_{0}^{2}+R_{1} Q_{1}^{2}+ \\
& +2 R_{1} Q_{1} \Delta Q_{1}+R_{1} \Delta Q_{1}^{2}=a_{0}+a_{1} Q_{1}+a_{2} Q_{1}^{2}+ \\
& +\left(a_{1}+2 a_{2} Q_{1}\right) \Delta Q_{1}+a_{2} \Delta Q_{1}^{2} \pm h_{n 1}
\end{aligned}
$$

Subtracting Eq. (4) from Eq. (6) achieves the following:

$$
\begin{aligned}
& 2 R_{0} Q_{0} \Delta Q_{0}+R_{0} \Delta Q_{0}{ }^{2}+2 R_{1} Q_{1} \Delta Q_{1}+R_{1} \Delta Q_{1}{ }^{2}= \\
& =\left(a_{1}+2 a_{2} Q_{1}\right) \Delta Q_{1}+a_{2} \Delta Q_{1}^{2}
\end{aligned}
$$

To discuss the influence of the changes of $\Delta Q_{2}$ on $\Delta Q_{1}$, we use Eq. (3) simultaneously with Eq. (7) to eliminate $\Delta Q_{0}$, thereby obtaining the following:

$$
\begin{aligned}
& \left(R_{0}+R_{1}-a_{2}\right) \Delta Q_{1}^{2}+\left(2 R_{0} Q_{0}+2 R_{0} \Delta Q_{2}+2 R_{1} Q_{1}-\right. \\
& a_{1}-2 a_{2} Q_{1} \Delta Q_{1}+\left(R_{0} \Delta Q_{2}^{2}+2 R_{0} Q_{0} \Delta Q_{2}\right)=0
\end{aligned}
$$

Eq. (8) can be considered as a quadratic equation of $\Delta Q_{1}$. According to the root solution formula, the following can be obtained:

$\Delta Q_{1}=\frac{-\left(N+E \Delta Q_{2}\right) \pm \sqrt{N^{2}+M \Delta Q_{2}-K \Delta Q_{2}}}{P}$

where: $\quad E=2 R_{0} \quad, \quad P=2\left(R_{0}+R_{1}-a_{2}\right)$, $N=2 R_{0} Q_{0}+2 R_{1} Q_{1}-a_{1}-2 a_{2} Q_{1}, M=8 R_{0} Q_{2}\left(a_{2}-R_{1}\right)-4 a_{1} R_{0}$, $K=4\left(R_{1}-a_{2}\right) R_{0}$. Whether + or - is used in Eq. (9) is discussed below. The term $\left(N+E \Delta Q_{2}\right)$ in Eq. (9) is expanded as follows:

$N+E \Delta Q_{2}=2 R_{0} Q_{0}+2 R_{1} Q_{1}-a_{1}-2 a_{2} Q_{1}+2 R_{0} \Delta Q_{2}$

The adjustment limit of air quantity for the right-wing fan is the case in which the right-wing fan has no air.
Meanwhile, $\Delta Q_{2}=-Q_{2}$, so that $\Delta Q_{2} \geq-Q_{2}$. Then, the following can be obtained:

$$
\begin{aligned}
& 2 R_{0} Q_{0}+2 R_{1} Q_{1}-a_{1}-2 a_{2} Q_{1}+2 R_{0} \Delta Q_{2} \geq \\
& \geq 2 R_{0} Q_{0}+2 R_{1} Q_{1}-a_{1}-2 a_{2} Q_{1}-2 R_{0} Q_{2}
\end{aligned}
$$

Owing to the fact that $Q_{0}=Q_{1}+Q_{2}$, Eq. (11) can further change into the following:

$$
\begin{aligned}
& 2 R_{0} Q_{0}+2 R_{1} Q_{1}-a_{1}-2 a_{2} Q_{1}+2 R_{0} \Delta Q_{2} \geq 2 R_{0} Q_{1}+ \\
& +2\left(R_{1} Q_{1}-\frac{a_{1}}{2}-a_{2} Q_{1}\right)
\end{aligned}
$$

According to the actual characteristic curve of the major fan, the following can be obtained:

$$
R_{1} Q_{1}-\frac{a_{1}}{2}-a_{2} Q_{1} \geq 0
$$

Accordingly, the following in Eq. (9) is obtained:

$$
\begin{aligned}
& N+E \Delta Q_{2}=2 R_{0} Q_{0}+2 R_{1} Q_{1}- \\
& -a_{1}-2 a_{2} Q_{1}+2 R_{0} \Delta Q_{2}>0
\end{aligned}
$$

$E, P, N, M$, and $K$ in Eq. (9) remain constant at a moment for a ventilation system. As viewed from a mathematical perspective, it is assumed that "-" is taken in Eq. (9), and the positive and negative of Eq. (9) only depend on the positive and negative of $P$. If $P$ is positive, then the value of Eq. (9) is a constant negative. If $P$ is negative, then the value of Eq. (9) is a constant positive. That is, the left-wing air quantity only increases or decreases no matter how the right-wing air quantity changes, which is inconsistent with the actual production situation. Therefore, the preceding assumption is incorrect and "+" is used in Eq. (9).

According to $\Delta Q_{0}=\Delta Q_{1}+\Delta Q_{2}$, the following can be obtained:

$$
\begin{aligned}
& \Delta Q_{0}=\frac{-\left(E \Delta Q_{2}+N\right)+\sqrt{N^{2}+M \Delta Q_{2}-K \Delta Q_{2}{ }^{2}}}{P}+\Delta Q_{2}= \\
& =\frac{H \Delta Q_{2}-N+\sqrt{N^{2}+M \Delta Q_{2}-K \Delta Q_{2}^{2}}}{P}
\end{aligned}
$$

where $H=2\left(R_{1}-a_{2}\right)$.

In summary, the theoretical interaction equations for the right-wing air quantity and total air quantity in the mine can be obtained as follows:

$$
\left\{\begin{array}{l}
\Delta Q_{1}=\frac{-\left(E \Delta Q_{2}+N\right)+\sqrt{N^{2}+M \Delta Q_{2}-K \Delta Q_{2}^{2}}}{P} \\
\Delta Q_{0}=\frac{H \Delta Q_{2}-N+\sqrt{N^{2}+M \Delta Q_{2}-K \Delta Q_{2}^{2}}}{P}
\end{array}\right.
$$

\subsection{Approximate Interaction Equation}

The quadratic term of $\Delta Q_{1}$ exists on both sides of Eq. (6). The values of $R_{1}$ and $a_{2}$ are usually extremely small in 
actual production, and the value of the quadratic term of $\Delta Q_{1}$ is also smaller than the other terms of the equation. Thus, the quadratic term of $\Delta Q_{1}$ can be seen as the secondorder small variable. Ignoring the second-order small variable in Eq. (6), we obtain the following:

$$
\begin{aligned}
& R_{0} Q_{0}{ }^{2}+2 R_{0} Q_{0} \Delta Q_{0}+R_{1} Q_{1}^{2}+2 R_{1} Q_{1} \Delta Q_{1}= \\
& =a_{0}+a_{1} Q_{1}+a_{2} Q_{1}{ }^{2}+\left(a_{1}+2 a_{2} Q_{1}\right) \Delta Q_{1} \pm h_{n 1}
\end{aligned}
$$

Eq. (17) minus Eq. (4) obtains the following:

$$
2 R_{0} Q_{0} \Delta Q_{0}+2 R_{1} Q_{1} \Delta Q_{1}=\left(a_{1}+2 a_{2} Q_{1}\right) \Delta Q_{1}
$$

Eq. (18) is simultaneously used with Eq. (3) to obtain the following:

$$
\begin{gathered}
\Delta Q_{1}=-\frac{1}{1+\frac{R_{1} Q_{1}-\frac{a_{1}}{2}-a_{2} Q_{1}}{R_{0} Q_{0}} \Delta Q_{2}} \\
\Delta Q_{0}=\frac{\frac{R_{1} Q_{1}-\frac{a_{1}}{2}-a_{2} Q_{1}}{R_{0} Q_{0}}}{1+\frac{R_{1} Q_{1}-\frac{a_{1}}{2}-a_{2} Q_{1}}{R_{0} Q_{0}}} \Delta Q_{2} \\
\text { If } B=\frac{R_{1} Q_{1}-\frac{a_{1}}{2}-a_{2} Q_{1}}{R_{0} Q_{0}} \text { is used in Eq. (19) and (20), }
\end{gathered}
$$

then the approximate interaction equations for the rightwing air quantity and total air quantity in the mine can be obtained as follows:

$$
\left\{\begin{array}{l}
\Delta Q_{1}{ }^{\prime}=-\frac{1}{1+B} \Delta Q_{2} \\
\Delta Q_{0}{ }^{\prime}=\frac{B}{1+B} \Delta Q_{2}
\end{array}\right.
$$

If $\Delta Q_{0}=0$ exists in Eq. (7), then $R_{1}=a_{2}$ and $a_{1}=0$ can be obtained, and vice versa. Moreover, $\Delta Q_{1}=-\Delta Q_{2}$ can be obtained according to Eq. (3). In this case, the opposite direction airflow exists in the airway of the left wing of the mine, and the entire left wing becomes an intake route of the right-wing major fan. This arrangement is prohibited in coal mines because it may cause a major accident.

Evidently, the derived theoretical interaction equation is nonlinear, while the approximate interaction equation which ignores the second-order small variable is linear. The approximate interaction equation is simpler and more convenient in treating practical problems than the theoretical interaction equation, but the magnitude error produced by the approximate interaction equation is unknown.

We can qualitatively consider that the increase of the right-wing air quantity will cause a decrease of the leftwing air quantity and an increase of total air quantity of the mine in a dual-wing diagonal ventilation system from Eq.
(20). In turn, the decrease of the right-wing air quantity causes an increase of the left-wing air quantity and decrease of the total air quantity of the mine. This condition reflects the interaction law of two wings in a dual-wing diagonal ventilation system.

\section{CASE STUDY \\ 4.1 Interaction of Fan Joint Operation in Dual-Wing Diagonal Ventilation System}

The Qianjiaying mine in China is taken as an example for further analysis on the above research contents. The simplified ventilation system of the mine is shown in Fig. 2. According to the mine production conditions, the following are obtained by calculation:

The resistance of common airway $\left(R_{0}\right)$ is 0.0057 $\mathrm{Ns}^{2} / \mathrm{m}^{8}$, that of the west-wing airway $\left(R_{1}\right)$ is $0.1410 \mathrm{Ns}^{2} / \mathrm{m}^{8}$, and that of the east-wing airway $\left(R_{2}\right)$ is $0.1268 \mathrm{Ns}^{2} / \mathrm{m}^{8}$. The blade angle of the west-wing major fan is $40^{\circ}$, the fitting equation of the static-pressure characteristic curve is $h_{f S I}=863.04+42.28 Q-0.5766 Q^{2}$, and the air quantity $\left(Q_{1}\right)$ is $70 \mathrm{~m}^{3} / \mathrm{s}$. The blade angle of the east-wing major fan is $35^{\circ}$, the fitting equation of the static-pressure characteristic curve is $h_{f s I I}=905.6+48.35 Q-0.6314 Q^{2}$, and the air quantity $\left(Q_{2}\right)$ is $75 \mathrm{~m}^{3} / \mathrm{s}$. The total air quantity of the mine $\left(Q_{0}\right)$ is $145 \mathrm{~m}^{3} / \mathrm{s}$.

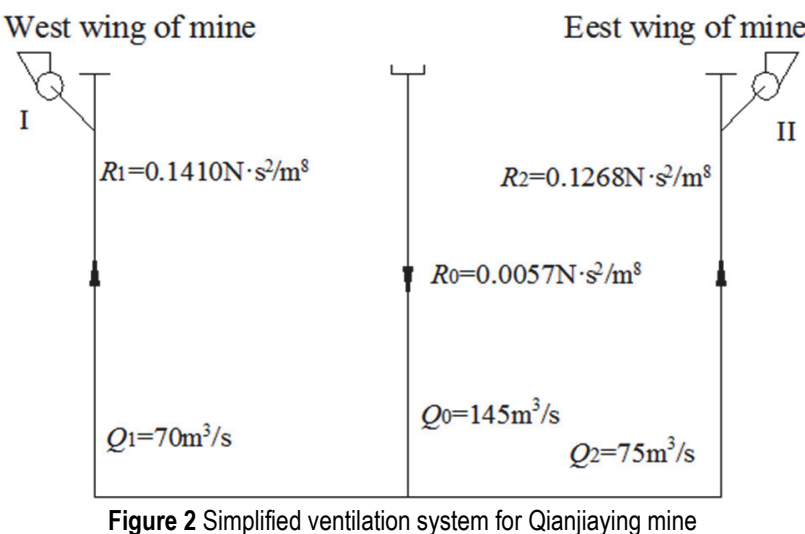

According to the known conditions, the air quantity of the mine's east wing can be adjusted by $\Delta Q_{2}$ to meet the new requirements of the production plan. Under the condition of the west-wing undergoing no adjustment, the change laws of the west-wing air quantity and total air quantity of the mine are analyzed according to the theory in Section 2. $a_{1}=42.281$ and $a_{2}=-0.5766$ can be obtained from the fitting equation of the characteristic curve of the west-wing major fan.

The influences from the air quantity adjustment of the east wing on the air quantity of the west wing and total air quantity of the mine are shown in Fig. 3 and Fig. 4. The absolute error between the theoretical equation and approximate equation changes with the air quantity adjustment of the east wing, as shown in Fig. 5 and Fig. 6.

As shown in Fig. 3 and Fig. 4, the west-wing air quantity is reduced, but the total air quantity increases when the east-wing air quantity increases. When the eastwing air quantity decreases, the situation is the opposite. In addition, the change magnitude of the total air quantity 
caused by the east-wing air quantity changes is significantly larger than that of the west-wing air quantity.

In this case, the theoretical interaction and approximate interaction equations are calculated in combination with other parameters, as shown in Eq. (22) and Eq. (23):

$$
\left\{\begin{array}{l}
\Delta Q_{1}{ }^{\prime}=-\frac{-\left(0.0114 \Delta Q_{2}+59.836\right)+\sqrt{3580.347-3.418 \Delta Q_{2}-0.016 \Delta Q_{2}{ }^{2}}}{1.447} \\
\Delta Q_{0}{ }^{\prime}=\frac{1.435 \Delta Q_{2}+59.836+\sqrt{3580.347-3.418 \Delta Q_{2}-0.016 \Delta Q_{2}{ }^{2}}}{1.447}
\end{array}\right.
$$

$\left\{\begin{array}{l}\Delta Q_{1}{ }^{\prime}=-\frac{1}{36.198} \Delta Q_{2} \\ \Delta Q_{0}{ }^{\prime}=\frac{35.198}{36.198} \Delta Q_{2}\end{array}\right.$

Fig. 3 and Fig. 5 show that the result of the approximate equation is larger than that of the theoretical equation in the research on the influences of the east-wing air quantity changes on the west-wing air quantity. The larger the east-wing air quantity change is (i.e., the larger $\left|\Delta Q_{2}\right|$ is), the larger the absolute error becomes. However, the absolute error is not smaller relative to the theoretical change of the west-wing air quantity. Therefore, the influence of the second-order small variable should be considered in the research process.

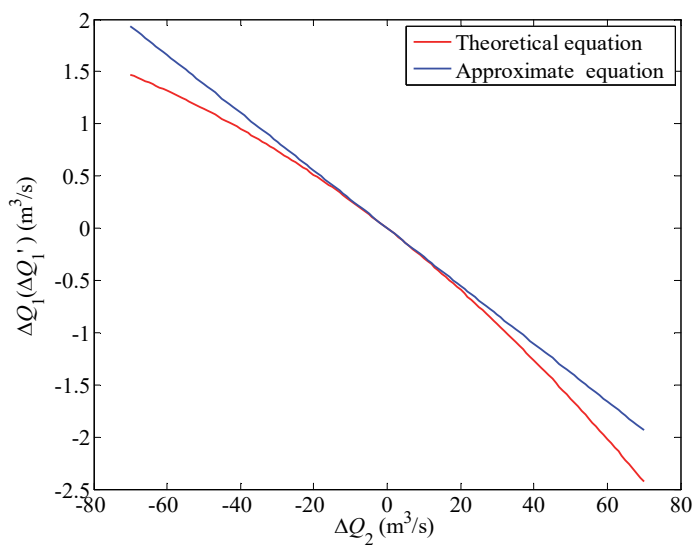

Figure 3 Curve of west-wing air quantity change in Qianjiaying mine

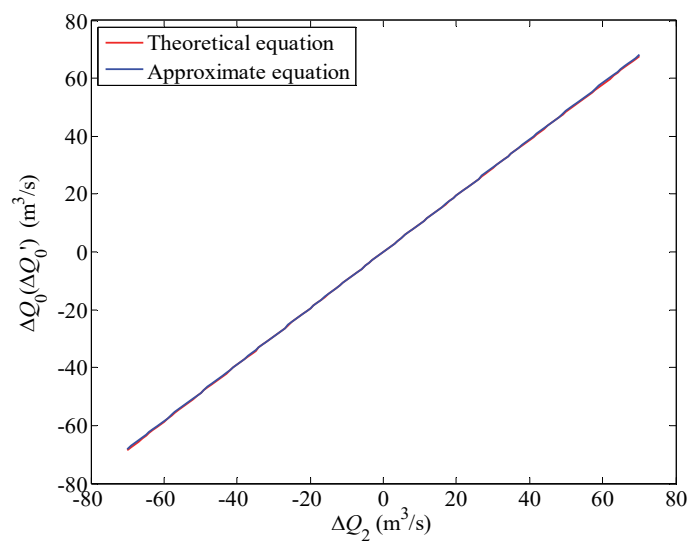

Figure 4 Curve of total air quantity change in Qianjiaying mine

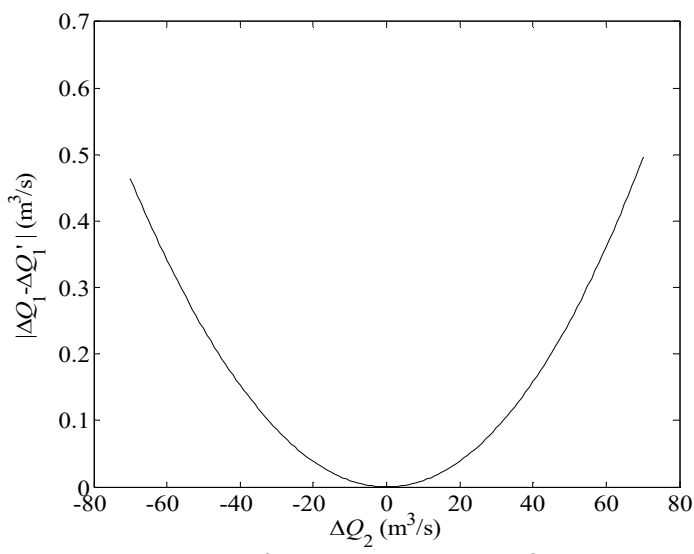

Figure 5 Absolute error of west-wing air quantity in Qianjiaying mine

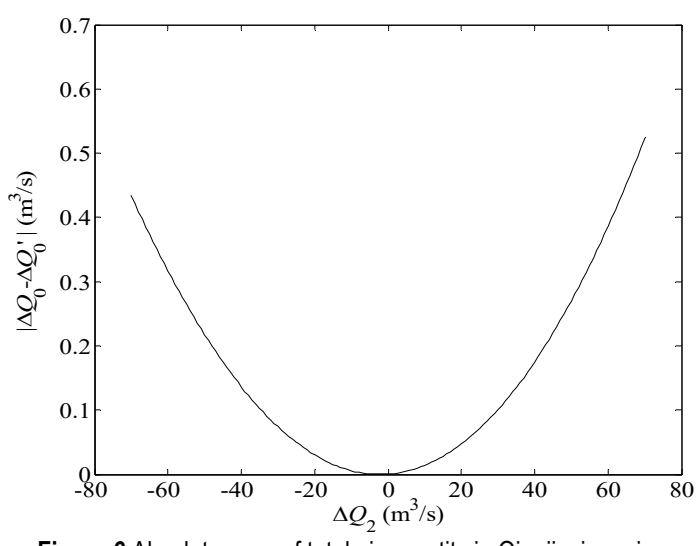

Figure 6 Absolute error of total air quantity in Qianjiaying mine

Fig. 4 and Fig. 6 show that the larger the east-wing air quantity change is (i.e., the larger the $\left|\Delta Q_{2}\right|$ is), the larger is the absolute error of the total air quantity in Qianjiaying mine. However, this absolute error is small relative to the theoretical value of the total mine air quantity change, thereby indicating that the influence of second-order small variable can be ignored in the research process.

\subsection{Error Analysis}

In the case of Qianjiaying mine, the change laws of the air quantity are described above under the condition of $R_{0}$ $=0.0057 \mathrm{Ns}^{2} / \mathrm{m}^{8}$. To study the influences of changes of $R_{0}$ on the error of the approximate interaction equation compared with the theoretical interaction equation, we perform the following analysis. The $R_{0}$ is set as 0.006 , $0.008,0.01$, and $0.02 \mathrm{Ns}^{2} / \mathrm{m}^{8}$ for comparison with $R_{0}=$ $0.0057 \mathrm{Ns}^{2} / \mathrm{m}^{8}$ in the case. Based on the principles of fan performance, air quantity and air pressure remain unchanged, and the dual-wing resistance of $R_{1}$ and $R_{2}$ are back-calculated under different $R_{0}$. The various parameters 
are substituted into Eq. (16) and Eq. (21) to obtain

$$
R_{0}=0.006 \mathrm{Ns}^{2} / \mathrm{m}^{8}
$$

theoretical and approximate interaction equations under

different $R_{0}$, as follows:

$\left\{\begin{array}{l}\Delta Q_{1}{ }^{\prime}=-\frac{-\left(0.012 \Delta Q_{2}+59.643\right)+\sqrt{3557.287-3.591 \Delta Q_{2}-0.017 \Delta Q_{2}{ }^{2}}}{1.44} \\ \Delta Q_{0}{ }^{\prime}=\frac{1.431 \Delta Q_{2}+59.643+\sqrt{3557.287-3.591 \Delta Q_{2}-0.017 \Delta Q_{2}{ }^{2}}}{1.44}\end{array}\right.$

$\left\{\begin{array}{l}\Delta Q_{1}^{\prime}=-\frac{1}{34.278} \Delta Q_{2} \\ \Delta Q_{0}^{\prime}=\frac{33.278}{34.278} \Delta Q_{2}\end{array}\right.$

$R_{0}=0.008 \mathrm{Ns}^{2} / \mathrm{m}^{8}$

$\left\{\begin{array}{l}\Delta Q_{1}{ }^{\prime}=-\frac{-\left(0.016 \Delta Q_{2}+59.103\right)+\sqrt{3493.165-4.749 \Delta Q_{2}-0.023 \Delta Q_{2}{ }^{2}}}{1.43} \\ \Delta Q_{0}{ }^{\prime}=\frac{1.415 \Delta Q_{2}+59.103+\sqrt{3493.165-4.749 \Delta Q_{2}-0.023 \Delta Q_{2}{ }^{2}}}{1.43}\end{array}\right.$

$\left\{\begin{array}{l}\Delta Q_{1}^{\prime}=-\frac{1}{25.475} \Delta Q_{2} \\ \Delta Q_{0}^{\prime}=\frac{24.475}{25.475} \Delta Q_{2}\end{array}\right.$

$R_{0}=0.01 \mathrm{Ns}^{2} / \mathrm{m}^{8}$

$\left\{\begin{array}{l}\Delta Q_{1}{ }^{\prime}=-\frac{-\left(0.02 \Delta Q_{2}+58.423\right)+\sqrt{3413.247-5.883 \Delta Q_{2}-0.028 \Delta Q_{2}{ }^{2}}}{1.42} \\ \Delta Q_{0}{ }^{\prime}=\frac{1.397 \Delta Q_{2}+58.423+\sqrt{3413.247-5.883 \Delta Q_{2}-0.028 \Delta Q_{2}{ }^{2}}}{1.42}\end{array}\right.$

$\left\{\begin{array}{l}\Delta Q_{1}^{\prime}=-\frac{1}{20.146} \Delta Q_{2} \\ \Delta Q_{0}^{\prime}=\frac{19.146}{20.146} \Delta Q_{2}\end{array}\right.$

$R_{0}=0.02 \mathrm{Ns}^{2} / \mathrm{m}^{8}$ :

$\left\{\begin{array}{l}\Delta Q_{1}=-\frac{-\left(0.04 \Delta Q_{2}+55.443\right)+\sqrt{3073.926-11.261 \Delta Q_{2}-0.053 \Delta Q_{2}{ }^{2}}}{1.42} \\ \Delta Q_{0}=\frac{1.313 \Delta Q_{2}+55.443+\sqrt{3073.926-11.261 \Delta Q_{2}-0.053 \Delta Q_{2}{ }^{2}}}{1.42}\end{array}\right.$

$\left\{\begin{array}{l}\Delta Q_{1}^{\prime}=-\frac{1}{9.559} \Delta Q_{2} \\ \Delta Q_{0}^{\prime}=\frac{8.559}{9.559} \Delta Q_{2}\end{array}\right.$

The graphs of the west-wing air quantity that changes with the east-wing air quantity under different $R_{0}$ are shown in Fig. 7. As shown in this figure, $\Delta Q_{1}$ is negatively correlated with $\Delta Q_{2}$, but with the increase of $R_{0}$, the change amplitude of the west-wing air quantity increases under the same change of the east-wing air quantity. 


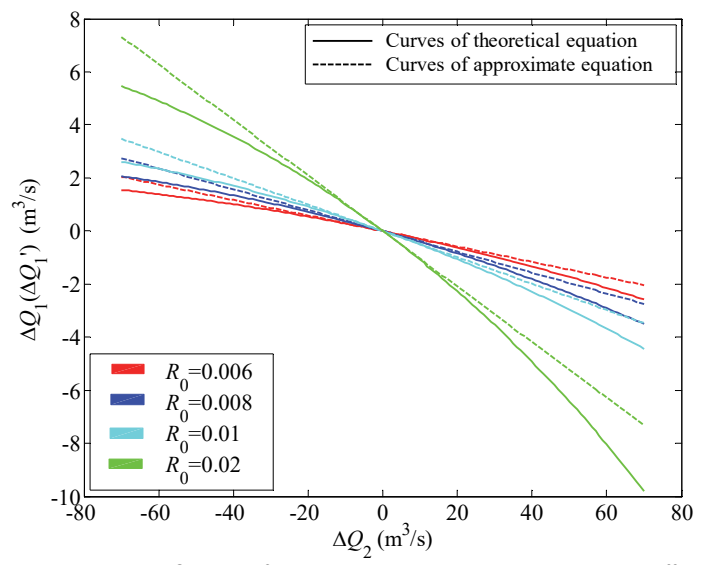

Figure 7 Curves of west-wing air quantity change under different $R_{0}$

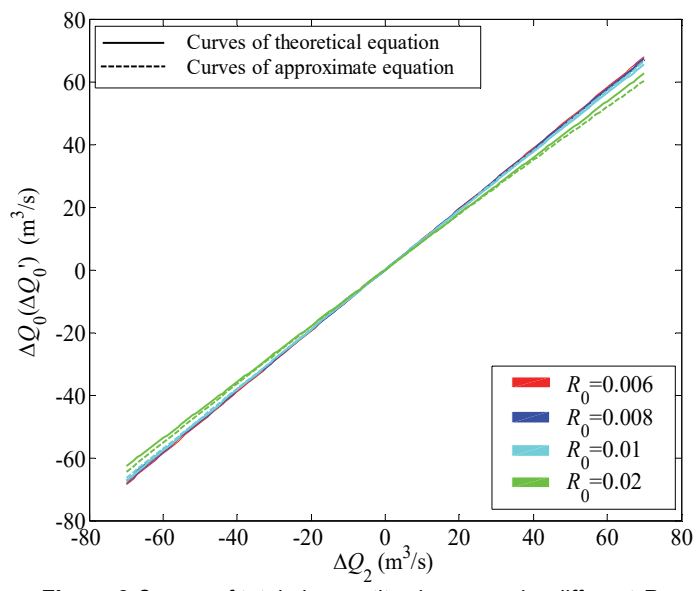

Figure 8 Curves of total air quantity change under different $R_{0}$

Furthermore, the larger the resistance of airway in the common airway is, the greater is the influence degree of the east-wing air quantity changes on the west-wing air quantity. The graphs of the total mine air quantity changing with the east-wing air quantity under different $R_{0}$ are shown in Fig. 8. This figure indicates that $\Delta Q_{0}$ presents a positive correlation with $\Delta Q_{2}$.

\subsubsection{Error Analysis of Change of West-Wing Air Quantity}

The absolute and relative errors between the theoretical air quantity change and approximate air quantity change can be calculated by Eq. (32) and Eq. (33), respectively.

$$
\text { Absolute error }=\left|\Delta Q^{\prime}-\Delta Q\right|
$$

Relative error $=\frac{\left|\Delta Q^{\prime}-\Delta Q\right|}{|\Delta Q|} \times 100 \%$

where $\Delta Q$ is theoretical air quantity change, which is calculated by the theoretical interaction equation, and $\Delta Q^{\prime}$ is approximate air quantity change, which is calculated by the approximate interaction equation.

Under the condition of different $R_{0}$, the change laws of absolute error $\left(\left|\Delta Q_{1}-\Delta Q_{1}^{\prime}\right|\right)$ for the west-wing air quantity change are shown in Fig. 9. This figure shows that the larger $R_{0}$ is, the larger is the absolute error between the theoretical value and approximate value of the west-wing air quantity changes, and the absolute error increases with the change of east-wing air quantity growing. However, the absolute error is not extremely large; when $\Delta Q_{2}$ is $70 \mathrm{~m}^{3} / \mathrm{s}$ and $R_{0}$ is $0.01 \mathrm{Ns}^{2} / \mathrm{m}^{8}$, the absolute error does not reach 2.5 $\mathrm{m}^{3} / \mathrm{s}$. Under the condition of $\Delta Q_{2}=40 \mathrm{~m}^{3} / \mathrm{s}$ and $R_{0}=0.006$ $\mathrm{Ns}^{2} / \mathrm{m}, \Delta Q_{1}=-1.34 \mathrm{~m}^{3} / \mathrm{s}$ is obtained according to Eq. (24), $\Delta Q_{1}{ }^{\prime}=-1.1666 \mathrm{~m}^{3} / \mathrm{s}$ is obtained according to Eq. (25), and the absolute error of $\left|\Delta Q_{1}-\Delta Q_{1}^{\prime}\right|=0.1733 \mathrm{~m}^{3} / \mathrm{s}$ is obtained. Therefore, the relative error between the theoretical and approximate results reaches $12.9 \%$ according to Eq. (33).

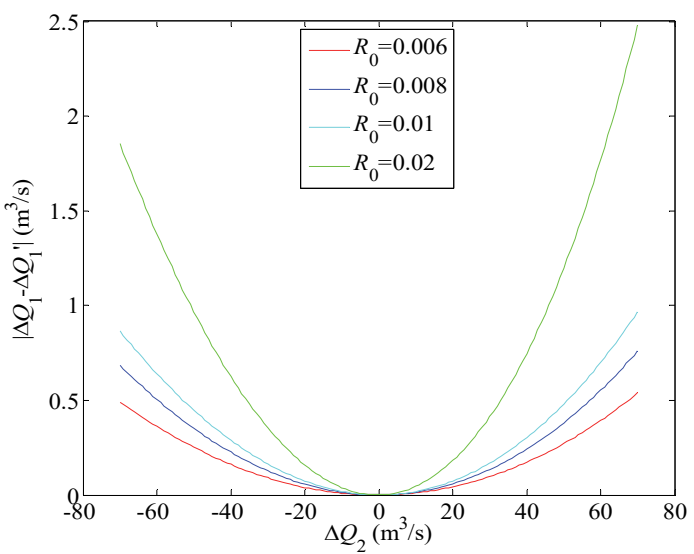

Figure 9 Absolute error of west-wing air quantity change under different $R_{0}$

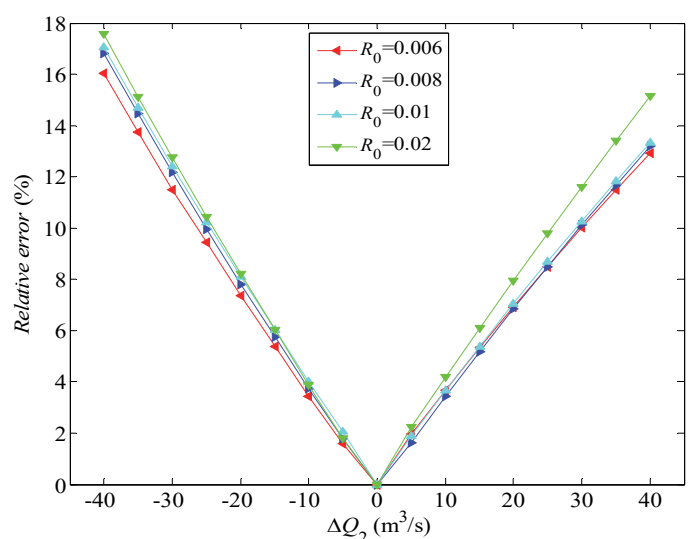

Figure 10 Relative error of west-wing air quantity change under different $R_{0}$

Similarly, when the east-wing air quantity changes within $40 \mathrm{~m}^{3} / \mathrm{s}$, the relative errors between the theoretical and approximate results are calculated. The relative error changes for the west-wing air quantity change are shown in Fig. 10. As shown in this figure, the relative error between the theoretical and approximate results for the east-wing air quantity changes are relatively large; the larger the east-wing air quantity change $\left(\left|\Delta Q_{2}\right|\right)$ is, the larger the relative error is. When $\left|\Delta Q_{2}\right|$ reaches $15 \mathrm{~m}^{3} / \mathrm{s}$, the relative error is over $5 \%$, and when $\left|\Delta Q_{2}\right|$ reaches $30 \mathrm{~m}^{3} / \mathrm{s}$, the relative error is over $10 \%$. Moreover, Fig. 10 illustrates that the relative error increases with the increase of $R_{0}$ under the same $\Delta Q_{2}$.

Therefore, the larger the change of the east-wing air quantity is, the larger are the relative and absolute errors of the west-wing air quantity change caused by the approximate equation. Thus, adopting the theoretical equation considering the second-order small variable is preferable. 


\subsubsection{Error Analysis for Change of Total Air Quantity}

Under the condition of different $R_{0}$, the change laws of absolute error $\left(\left|\Delta Q_{0}-\Delta Q_{0}^{\prime}\right|\right)$ for the total air quantity changes are shown in Fig. 11. The figure shows that, under the condition of increasing east-wing air quantity, with the increase of $R_{0}$, the absolute error between the theoretical and approximate values of the total air quantity change grows. When the east-wing air quantity decreases, no significant law exists between the absolute error change and value of $R_{0}$, but the absolute error increases with the change in the increase of the east-wing air quantity. Similarly, under the condition of $\Delta Q_{2}=40 \mathrm{~m}^{3} / \mathrm{s}$ and $R_{0}=$ $0.006 \mathrm{Ns}^{2} / \mathrm{m}^{8}, \Delta Q_{0}=38.74 \mathrm{~m}^{3} / \mathrm{s}$ is obtained according to Eq. (24), $\Delta Q_{0}{ }^{\prime}=38.8331 \mathrm{~m}^{3} / \mathrm{s}$ is obtained according to Eq. (25), and the absolute error of $\left|\Delta Q_{0}-\Delta Q_{0}{ }^{\prime}\right|=0.090 \mathrm{~m}^{3} / \mathrm{s}$ is obtained.

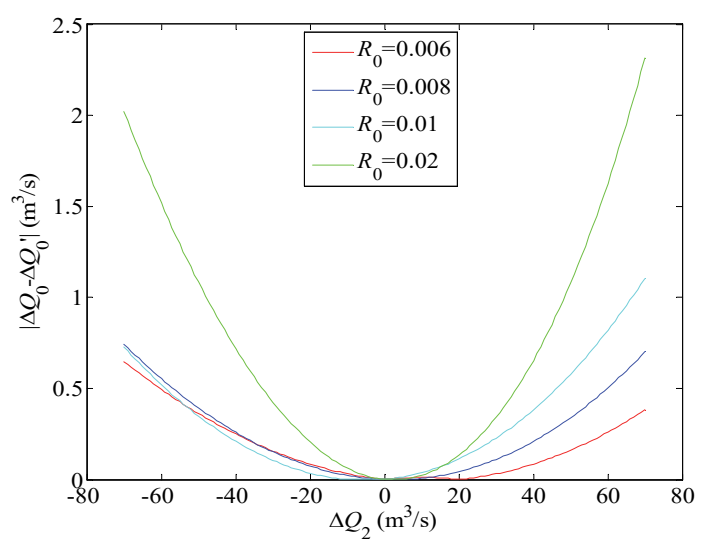

Figure 11 Absolute error of total air quantity change under different $R_{0}$

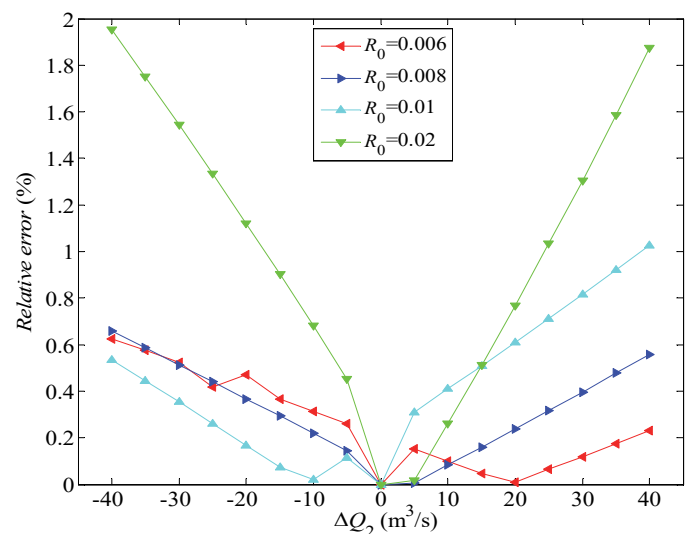

Figure 12 Relative error of total air quantity change under different $R_{0}$

Therefore, the relative error between the calculated theoretical result and approximate result is only $0.2 \%$ according to Eq. (33). Similarly, when the east-wing air quantity changes within $40 \mathrm{~m}^{3} / \mathrm{s}$, the relative errors are calculated. The relative error changes for the total air quantity change are shown in Fig. 12. This figure shows that the relative error between the theoretical and approximate results of the total air quantity change is relatively small and less than $2 \%$. The larger the east-wing air quantity change $\left(\left|\Delta Q_{2}\right|\right)$ is, the larger the relative error is. The relative error increases with the increase of $R_{0}$ under the condition of $\left|\Delta Q_{2}\right|>15 \mathrm{~m}^{3} / \mathrm{s}$. Therefore, the relative error caused by the approximate equation is not large.

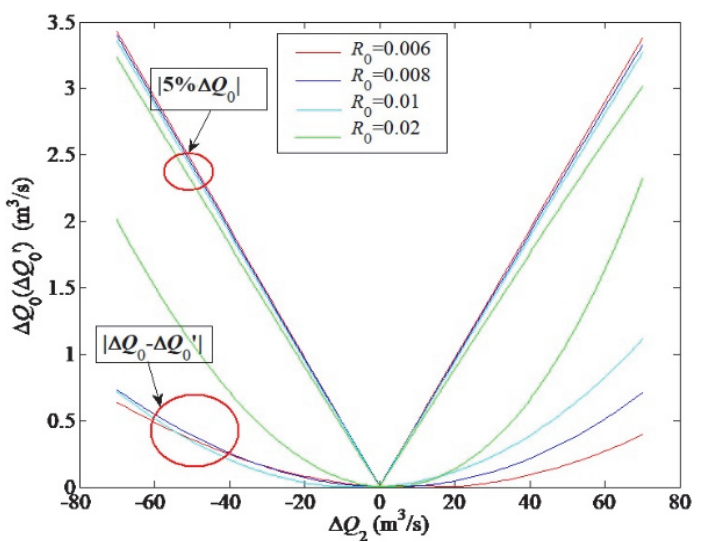

Figure 13 Curves of $\left|\Delta Q_{0}-\Delta Q_{0}{ }^{\prime}\right|$ and curves of $\left|5 \% \Delta Q_{0}\right|$ under different $R_{0}$

To verify this judgment, we add the curves of $\left|5 \% \Delta Q_{0}\right|$ under different $R_{0}$ to Fig. 11, as shown in Fig. 13. Clearly, the curves of the absolute error between the theoretical and approximate equations are much lower than the curves of $\left|5 \% \Delta Q_{0}\right|$ under different $R_{0}$, thereby proving that the relative error caused by the approximate equation is not larger than $5 \%$. Thus, the approximate equation can be used for convenient calculation in engineering.

\section{CONCLUSIONS}

To explore the interaction laws of two wings in a dualwing diagonal ventilation system, we derived the theoretical interaction equation (nonlinear) and approximate interaction equation (linear), and the error between them was examined through the example of the Qianjiaying coal mine. The following conclusions were obtained:

(1) Considering the second-order small variables, we derived the theoretical interaction equation of two wings in the dual-wing diagonal ventilation system. Ignoring the second-order small variables, we obtained the approximate interaction equation of the two wings in the dual-wing diagonal ventilation system. By means of computational analysis and example analysis methods, the influence law of the two-wing ventilation system on the air volume of the two-wing ventilation system is verified. The air quantity increase in a wing decreases the air quantity in the other wing. The greater the resistance of the common airway is, the greater is the influence degree. The air quantity increase in a wing also results in the increase of the total air quantity of the mine, and the change amplitude of the total air quantity of the mine decreases with the increase in the resistance of the common airway.

(2) The changes in the absolute and relative errors for the left-wing air quantity which were due to the approximate interaction equation were analyzed. Both types of error increase with the increase of right-wing air quantity change and increase of $R_{0}$. The absolute error was not extremely large, and the absolute error did not reach $2.5 \mathrm{~m}^{3} / \mathrm{s}$ when $\Delta Q_{2}$ was $70 \mathrm{~m}^{3} / \mathrm{s}$ and $R_{0}$ was $0.01 \mathrm{Ns}^{2} / \mathrm{m}^{8}$. The increase magnitude of relative error was large. When $\left|\Delta Q_{2}\right|$ reached $15 \mathrm{~m}^{3} / \mathrm{s}$, the relative error was over $5 \%$, and when $\left|\Delta Q_{2}\right|$ reached $30 \mathrm{~m}^{3} / \mathrm{s}$, the relative error was over $10 \%$. Therefore, the theoretical interaction equation should be adopted in engineering.

(3) The changes in the absolute and relative errors of the total air quantity, which were due to the approximate 
interaction equation, were analyzed. When the right-wing air quantity increased, the absolute error increased with the increase of $R_{0}$. When the right-wing air quantity decreased, no significant law existed between the absolute error change and value of $R_{0}$, but the absolute error increased with the change in the increase of the right-wing air quantity. The relative error increased with the increase of $R_{0}$ under the condition of $\left|\Delta Q_{2}\right|>15 \mathrm{~m}^{3} / \mathrm{s}$. The relative error was relatively small at less than $5 \%$, and thus, the approximate interaction equation can be adopted for convenient calculation in engineering.

\section{REFERENCES}

[1] Xu, G., Jong, E. C., Luxbacher, K. D., et al. (2016). Effective utilization of tracer gas in characterization of underground mine ventilation networks. Process Safety and Environmental Protection, 99, 1-10. https://doi.org/10.1016/j.psep.2015.10.001

[2] Han, Y. Z., Cheng, W. M., Liu, H., et al. (2019). Treatment methods for natural wind pressure in mines with zonal ventilation system with diagonal branches: A case study of Wudong Coal Mine. Energy Sources, Part A: Recovery, Utilization, and Environmental Effects, 1-13. https://doi.org/10.1080/15567036.2019.1673512

[3] Sandoval-Pineda, J. M., Tamayo-Meza, P. A., Silva-Rivera, U. S., et al. (2017). CFD simulation of obstructed ventilation ports in a subway tunnel section. International Journal of Simulation Modelling, 16(3), 386-398. https://doi.org/10.2507/IJSIMM16(3)2.380

[4] Zhou, A. T. \& Wang, K. (2017). A transient model for airflow stabilization induced by gas accumulations in a mine ventilation network. Journal of Loss Prevention in the Process Industries, 47, 104-109. https://doi.org/10.1016/j.jp.2017.02.014

[5] Morar, M. S., Radu, S. M., Lupu, C., et al. (2017). Optimization of underground environment by improving the management of ventilation networks. Environmental Engineering and Management Journal, 16(6), 1409-1414. https://doi.org/10.30638/eemj.2017.153

[6] Zhou, L. H., Yuan, L. M., Thomas, R., et al. (2017). Determination of velocity correction factors for real-time air velocity monitoring in underground mines. International Journal of Coal Science and Technology, 4(4), 322-332. https://doi.org/10.1007/s40789-017-0184-z

[7] Fang, L. F., Li, X. D., Yu, G. D., et al. (2016). Study on catastrophic air current early-warning and control system of coal mines. Journal of Engineering Science and Technology Review, 9(1), 36-43. https://doi.org/10.25103/jestr.091.06

[8] Akhtar S., Kumral M., \& Sasmito A. P. (2017) Correlating variability of the leakage characteristics with the hydraulic performance of an auxiliary ventilation system. Building and Environment, 121, 200-214. https://doi.org/10.1016/j.buildenv.2017.05.029

[9] Wang, K., Jiang, S. G., Ma, X. P., et al. (2016). An automatic approach for the control of the airflow volume and concentrations of hazardous gases in coal mine galleries. Journal of Loss Prevention in the Process Industries, 43, 676-687. https://doi.org/10.1016/j.jp.2016.03.029

[10] Wei, L. J., Zhou, F. B., Cheng, J. W., et al. (2015). Classification of structural complexity for mine ventilation networks. Complexity, 21, 21-34. https://doi.org/10.1002/cplx.21538

[11] Jia, T. G. \& Liu, J. (2009). Stability of mine ventilation system based on multiple regression analysis. Mining Science Technology, 19, 463-466.

\section{https://doi.org/10.1016/s1674-5264(09)60086-7}

[12] Hurtado, J. P., \& Acuña, E. I. (2015). CFD analysis of 58 Adit main fans parallel installation for the 2015 - 2019 underground developments of the new level mine project. Applied Thermal Engineering, 90, 1109-1118. https://doi.org/10.1016/j.applthermaleng.2015.05.014

[13] Zhang, X. W. (2014). Mine ventilation diagonal parallel interaction analysis. Modern Industrial Economy and Informatization, 4(14):85-86.

[14] Wang, Y. J. (1984). Characteristics of multiple-fan ventilation networks. Geotechnical and Geological Engineering, 2(3), 229-243. https://doi.org/10.1007/BF00881112

[15] Gushchin, A. M. (1984). Using methods of differential calculus to estimate the influence of the combined operation of ventilators on the ventilation of mine workings. Soviet Mining, 20(3), 206-211. https://doi.org/10.1007/bf02515203

[16] Sarac, S. \& Sensogut, C. (2000). Mathematical solutions to the multiple-fan ventilation systems. Journal South African Institute of Mining and Metallurgy, 100(3), 1-6.

[17] Si, J. H., Chen, K. Y., Jiang, Z. C., et al. (2011). The interaction of multi-fan for the complex mine ventilation system based on limit analysis. Journal of the Mine Ventilation Society of South Africa, 64, 10-15.

[18] El-Nagdy, K. A. (2013). Stability of multiple fans in mine ventilation networks. International Journal of Mining Science and Technology, (4), 100-102. https://doi.org/10.1016/j.ijmst.2013.07.016

[19] Xu G., Huang J. X., Nie B. S., et al. (2018). Calibration of mine ventilation network models using the non-linear optimization algorithm. Energies, 11(1), 31. https://doi.org/10.3390/en11010031

[20] Li, B. X. (2019). Research and application of combined operation regulation and analytical method of multiple main fan. Mechanical Management and Development, 34(8), 165167.

[21] Luan, D. (2019). Research and application of joint operation adjustment and analysis method for multiple main fans. Coal and Chemical Industry, 42(6), 79-81.

[22] Bascompta, M., Sanmiquel, L., \& Zhang, H. (2018). Airflow stability and diagonal mine ventilation system optimization: A case study. Journal of Mining Science, 54(5), 813-820. https://doi.org/10.1134/S1062739118054927

[23] Alymenko, N. I. (2011). Aerodynamic parameters of ventilating passages joined-up with the main mine fan. Journal of Mining Science, 47(6), 814-823. https://doi.org/10.1134/S1062739147060141

\section{Contact information:}

Yongbo $\mathrm{CAl}, \mathrm{PhD}$ candidate

(Corresponding author)

School of Emergency Management and Safety Engineering,

China University of Mining and Technology-Beijing

No. 11, East Xueyuan Road, Haidian District,

Beijing 100083, P. R. China

E-mail: caiyongbo0328@126.com

Kai WANG, PhD, Professor

(Corresponding author)

School of Emergency Management and Safety Engineering,

China University of Mining and Technology-Beijing,

No. 11, East Xueyuan Road, Haidian District,

Beijing 100083, P. R. China

E-mail: kaiwang@cumtb.edu.cn 